\title{
La fortificación de los alimentos con ácido fólico disminuyó los defectos del tubo neural a nivel poblacional
}

\author{
Population-based reduction in neural-tube defects alter folic acid fortification of foods
}

De Wals P y col. N Engl J Med. 2007;357:135-42.

\section{Objetivo}

Determinar los cambios en la prevalencia de defectos del tubo neural en Canadá asociados a la implementación de la fortificación de la comida con ácido fólico.

\section{Diseño}

Estudio antes-después.

\section{Lugar}

Base de datos de siete provincias de Canadá.

\section{Pacientes}

La población de estudio incluyó los nacidos vivos, los fetos muertos y las finalizaciones electivas de embarazo por anomalías fetales de mujeres residentes en siete provincias de Canadá desde 1993 a 2002. El período de estudio fue dividido en tres: un período de previo a la fortificación, un período de fortificación parcial y un período de fortificación completa.

\section{Evaluación de los factores pronósticos}

Se evaluó la relación entre la incidencia basal de defectos del tubo neural de cada provincia y la magnitud de la disminución de la misma luego de la implementación de la fortificación.

\section{Resultados principales}

De un total de 1.9 millones de nacimientos, se registraron 2446 sujetos con defectos del tubo neural. La prevalencia de defectos del tubo neural disminuyó desde $1,58 / 1000$ nacimientos antes de la fortificación a 0,86/1000 nacimientos durante el período de fortificación completa, lo que representa una reduc- ción del 46\% (IC95\%; 40 a 51). La magnitud de la disminución fue proporcional a la tasa basal previa a la fortificación de cada provincia, y las diferencias geográficas casi desaparecieron luego de la fortificación. La tasa de reducción fue mayor para espina bífida (disminución del 53\%) que para anencefalia y encefalocele (disminución del $38 \%$ y $31 \%$, respectivamente). Ver tabla 1.

Tabla 1: prevalencia de defectos del tubo neural cada 1000 nacimientos, según el diagnóstico y el período de fortificación.

\begin{tabular}{l|c|c|c|c} 
Diagnóstico & $\begin{array}{c}\text { Previamente a } \\
\text { la fortificación }\end{array}$ & $\begin{array}{c}\text { Fortificación } \\
\text { parcial }\end{array}$ & $\begin{array}{c}\text { Fortificación } \\
\text { completa }\end{array}$ & Rate ratio* \\
\hline Anencefalia & 0,52 & 0,38 & 0,32 & 0,62 \\
\hline Encefalocele & 0,17 & 0,12 & 0,12 & 0,69 \\
\hline Espina bífida & 0,86 & 0,57 & 0,40 & 0,47 \\
\hline Total & 1,58 & 1,09 & 0,86 & 0,54 \\
\hline
\end{tabular}

"Comparando la tasa en el período de fortificación completa con la del período pre-fortificación.

\section{Conclusiones}

La fortificación de la comida con ácido fólico se asoció a una reducción significativa de los defectos del tubo neural en Canadá. La disminución fue mayor en áreas con tasas más altas de estos defectos.

Palabras claves: defecto del tubo neural, fortificación ácido fólico. Key words: neural-tube defects, folic acid fortification.

Fuente de financiamiento: Instituto canadiense de investigación de salud.

\section{Comentario}

La suplementación periconcepcional con ácido fólico es una medida de prevención primaria de defectos congénitos (defectos del cierre del tubo neural) conocida desde hace cerca de dos décadas. La recomendación ha sido suministrar ácido fólico periconcepcional a toda mujer que potencialmente pueda quedar embarazada $(0,4 \mathrm{mg} /$ día en mujeres sin antecedentes y $4 \mathrm{mg} / \mathrm{día}$ en pacientes con el antecedente de un hijo con defectos del tubo neural).

Sin embargo, el $50 \%$ de los embarazos no son planeados, por lo que la estrategia de suplementación periconcepcional falla. Por este motivo se propuso la fortificación de alimentos de consumo masivo para asegurar la ingesta de esta vitamina. La fortificación es una intervención sencilla, barata y de impacto poblacional, que abarca el período periconcepcional y no está librada a la voluntad de la mujer. Este último punto es el que mayores controversias éticas ha levantado.
La fortificación de los alimentos con ácido fólico se ha implementado en varios países demostrando ser una estrategia efectiva. Los resultados del presente son coincidentes con los de otros países donde fue introducida la fortificación de alimentos. En Chile, durante Enero de 2000 se inició un programa de fortificación de la harina de trigo. Con respecto al período previo a la fortificación, el análisis de tendencias mostró una disminución del $51 \%$ (27 a $66 \%$ ) en la incidencia de espina bífida, $y$ del $42 \%$ (10 a $63 \%$ ) en la de anencefalia ${ }^{1}$.

\section{Conclusión del comentador}

La fortificación de los alimentos con ácido fólico es una estrategia efectiva para la prevención primaria de ciertos defectos congénitos.

Gustavo Izbizky [ Servicio de Obstetricia del Hospital Italiano de Buenos Aires. gustavo.izbizky@ hospitalitaliano.org.ar ] Mar-Abr 2008. Comentado de: De Wals P, Tairou F, Van Allen MI, Uh SH, Lowry RB, Sibbald B, Evans JA, Van den Hof MC, Zimmer P, Crowley M, Fernandez B, Lee NS, Niyonsenga T. Reduction in neural-tube defects after folic acid fortification in Canada. N Engl J Med. 2007 Jul 12;357(2):135-42. PMID: 17625125. Disponible en URL: http://content.nejm.org/cgi/reprint/357/2/135.pdf (último acceso 11/04/2008).

\section{Referencia}

1. López-Camelo JS, Orioli IM, da Graça Dutra M, Nazer-Herrera J, Rivera N, Ojeda ME, Canessa A, Wettig E, Fontannaz AM, Mellado C, Castilla EE.Reduction of birth prevalence rates of neural tube defects after folic acid fortification in Chile. Am J Med Genet A. 2005 Jun 1;135(2):120-5. 